\title{
1 Creep on seismogenic faults: Insights from analogue earthquake
}

\section{2 experiments}

3 Matthias Rosenau*, Michael Rudolf and Onno Oncken

4 Helmholtz Centre Potsdam, German Research Centre for Geosciences (GFZ), Telegrafenberg, 14473

$5 \quad$ Potsdam (Germany)

6 *rosen@gfz-potsdam.de

7

8

$9 \quad$ Pre-print in EarthArXiv

10 License: CC BY 4.0

11

12 Please cite as:

13 Rosenau, M., Rudolf, and Oncken, O. (2019): Creep on seismogenic faults: Insights from analogue

14 earthquake experiments, EarthArXiv, https://dx.doi.org/10.31223/osf.io/24u5h

15 https://eartharxiv.org/24u5h

16

17 
Highlights

19 - Stick-slip experiments mimic seismogenic fault behavior

20 - Creep and earthquakes are not mutually exclusive fault styles

21 - Interseismic creep varies systematically with fault properties and stress state

22

23

24 Keywords

25 friction, faults, granular materials, aseismic creep, earthquakes, precursors 26 


\section{Abstract}

Tectonic faults display a range of slip behaviors including continuous and episodic slip covering rates of more than 10 orders of magnitude $(<\mathrm{mm} / \mathrm{a}$ to $>\mathrm{m} / \mathrm{s})$. The physical control of such kinematic observations remains ambiguous. To gain insight

31 into the slip behavior of brittle faults we performed laboratory stick-slip experiments using a rock analogue, granular material. We realized conditions under which our seismogenic fault analogue shows a variety of slip behaviors ranging from slow, quasi continuous creep to episodic slow slip to dynamic rupture controlled by a limited number of parameters. We explore a wide parameter space by varying loading rate from those corresponding to interseismic to postseismic rates and normal loads equivalent to hydrostatic to lithostatic conditions at seismogenic depth. The experiments demonstrate that significant interseismic creep and earthquakes may not be mutually exclusive phenomena and that creep signals vary systematically with the fault's seismic potential. Accordingly, the transience of interseismic creep scales with

41 fault strength and seismic coupling as well as with the maturity of the seismic cycle. Loading rate independence of creep signals suggests that mechanical properties of faults (e.g. seismic coupling) can be inferred from shortterm observations (e.g. releasing stress by continuous creep and/or transient slow slip instead of large earthquakes. 
Faults in the brittle part of the lithosphere may slip at rates ranging from slow, aseismic $(<1 \mathrm{~mm} / \mathrm{a})$ to fast, seismic $(>1 \mathrm{~m} / \mathrm{s})$ (Peng and Gomberg, 2010, and references therein). Moreover they might do so in either continuous (i.e. at constant rate) or transient fashion (at changing rate). Modern geodetic methods allow monitoring fault slip rates over time scales long enough to cover a significant part of the loading history (generally decades) for some fast loading settings like plate boundaries thereby constraining their kinematic behavior with unprecedented resolution (Moreno et al., 2010; Shirzaei and Bürgmann, 2013). Accordingly, a suite of slip behaviors has been observed ranging from continuous creep (e.g., Bokelman and Kovach, 2003) to transient creep (e.g. precursory and afterslip) (e.g. Bedford et al., 2013, Schurr et al., 2014) to episodic slip events at various rates (earthquakes, slow slip and non-volcanic tremor, low frequency earthquakes, creep events) (e.g. Rogers and Dragert, 2003; Ide et al., 2007). High fluid pressure has been identified as a controlling factor for slow slip phenomena (e.g., Peng and Gomberg, 2010, Moreno et al, 2014) but the underlying mechanisms and mechanics controlling which slip behavior prevails remain under determined. Importantly the physics of such faulting is often intrinsically undeterminable in nature because of the inaccessibility of the source and the ambiguity of the geophysical and kinematic observation which can be fitted by more than one theoretical models and/or set of model parameters.

Seismic and aseismic slip behavior are conventually viewed as mutually exclusive at a given location through time. Typically “ambivalent” fault slip behaviors are modelled as a result of the interaction of spatially separated sources, e.g. a seismogenic patch (asperity) embedded in an aseismic area (barriers) (e.g., Wei et al., 2013). However, a more integrative view of slow and fast slip phenomena might be possible where the 
slip behavior is non-unique (e.g. Peng and Gomberg, 2010). Indeed, there is recent evidence from longterm geodetic observations as well as contrasting geodeticseismological versus palaeoseismological observations that given fault areas might be more variable in their slip behaviors than conventionally believed. In particular we now have to acknowledge that a particular fault area may show aseismic creep or slow slip at one time while failing catastrophically in dynamic earthquake ruptures at others. Examples of spatially overlapping seismic and aseismic fault areas have been found along the Hayward fault in California U.S. (Lienkaemper at al., 2012, Shirzaei and Bürgmann, 2013) as well along the subduction megathrusts off Japan (Loveless and Meade, 2011, Kato et al, 2012) and Chile (Moreno et al, 2010, Ruiz et al, 2014). As a reaction to such evidence for non-unique slip behavior, existing friction laws have been adapted for example by allowing aseismic creep at low slip rates but dynamic weakening at high slip rates, e.g. in the presence of fluids (e.g. Noda and Lapusta, 2013).

We here contribute to the discussion of creep signals by means of experimental modeling seismogenic fault slip behavior using a labscale fault analogue under conditions relevant to natural faulting. We show that few parameters can control the rate and stability of fault slip and demonstrate that creeping faults can generate earthquakes. Showing the systematics by which this happens allows inferring information on the mechanical properties and state of the fault from kinematic observations.

\section{Friction regimes}

The most established view on the mechanics of faulting in the brittle regime $(<\mathrm{c}$. $350^{\circ} \mathrm{C}$ ) is represented by the rate-and-state dependent friction law (e.g. Scholz, 1998). This law opens avenues to explain fault slip behavior over a range of rates. In 
particular, it relates aseismic and seismic fault behavior to an intrinsic velocitystrengthening and velocity-weakening fault property, respectively. Accordingly, once static friction is overcome a velocity-weakening fault may weaken dynamically as slip accelerates resulting in a runaway effect or instability and nucleating an earthquake. In contrast, an increase of dynamic friction along a velocity strengthening fault inhibits earthquake nucleation at all times. Importantly, a third regime exists, in which most of the natural faults might actually be, which is characterized by velocity weakening under sufficiently low effective normal stress $\sigma_{\mathrm{n}}$ ' (e.g. near the surface or at high pore fluid pressures). In this regime, which is called the conditionally stable regime, fault slip is slow and stable under quasi-static loading while it can become unstable under dynamic loading (acceleration). "Sufficiently” low effective normal stress in the context of conditional stability means that the externally applied normal load minus the local pore fluid pressure is below a critical value $\sigma_{\mathrm{c}}$ :

$$
\sigma_{\mathrm{n}}{ }^{\prime}<\sigma_{\mathrm{c}}=k L /-(a-b)
$$

where $k$ is the spring stiffness in the original theoretical spring slider framework (or the stiffness of the medium in which the fault is embedded), $a$ the instantaneous change of friction following a loading rate change (so-called direct velocity effect) and $b$ the new steady state friction (so-called evolutionary effect) after the loading rate change which evolves over the characteristic slip distance $L$ (a physical interpretation is the size of asperities). The combined parameter $a$-b is negative for velocity weakening interfaces and positive for velocity-strengthening interfaces. Its absolute values are typically measured in the lab to be in the order of few percent for rocks and other materials (Scholz, 1998; and references therein). 
The laboratory-scale analogue earthquake experiments presented here have been performed in a ring shear tester setup (RST, Figure 1) where a granular material (dry rice) is sheared rotary in a velocity stepping test under imposed normal loads while shear stress is measured continuously (e.g. Rosenau et al., 2017, Rudolf et al., 2019). The rate of laboratory fault slip has been inferred from displacement records derived by particle image velocimetry (PIV, LaVision Strainmaster $\left.{ }^{\circledR}\right)$. For PIV analysis, a 12 bit monochrome charged-coupled device (CCD) camera shot sequential images of the analogue fault through a transparent shear cell at a frequency of $10 \mathrm{~Hz}$. The particle motions between successive images are then determined by cross-correlation of textural differences (i.e., gray values) formed by groups of particles within interrogation windows using a Fast Fourier Transform algorithm (Adam et al. 2003). Precision and accuracy of the PIV method is better than $0.1 \mathrm{px}$ of the original image which scales to the order of micrometer in the presented setup.

The stiffness of the loading system $(\sim 1.3 \mathrm{kN} / \mathrm{mm})$ together with $a-b(\sim-0.015)$ and $L$ ( $2 \mu \mathrm{m}$ ) for dry rice (Rosenau et al., 2009) predicts a critical (effective) normal stress of $\sigma_{\mathrm{c}}=8 \mathrm{kPa}$. Accordingly, we performed the tests at $1-16 \mathrm{kPa}$ normal load to explore the slip behavior of natural faults across the bifurcation. We refer to the high $(8,16 \mathrm{kPa})$ and low $(1,2,4 \mathrm{kPa})$ normal stress experiments as strong and weak faults, respectively.

Similarity of the experimental simulation with its natural prototype is ensured by keeping the following dimensionless numbers the same: (1) the friction coefficient (ratio between yield strength and normal stress) $\mu \sim 0.7$, (Byerlee, 1978) and (2) a friction rate parameter a-b -0.015 similar to rocks (e.g., Scholz, 1998) as well as (3) 
150 a dimensionless stress drop (ratio between rupture slip and length) of $\Delta \tau^{*} \sim 10^{-5}-10^{-4}$

151 similar to earthquakes (e.g., Scholz, 1989).

152 Applying a stress scale of 1:10.000, the setup generates slip instabilities (aka

153 “analogue earthquakes”, Figure 2) with stress drops which scale to 1 - $100 \mathrm{MPa}$ in

154 nature typical of large intra- and interplate earthquakes (Scholz, 1989; Hardebeck and

155 Aron, 2009) including precursory events of different scale (Figure 3). The strength of

156 the laboratory fault analogues can be interpreted in two way: Either representing (A)

157 different crustal depths at a given pore fluid pressure (i.e. weak = shallow, strong =

158 deep) or (B) representing different pore fluid pressures at a given depth. For example,

159 at typical seismogenic crustal depths of $5-15 \mathrm{~km}$ and typical rock densities of $2300-$

$1602700 \mathrm{~kg} / \mathrm{m}^{3}$, the experimental normal stresses (10 - $\left.160 \mathrm{MPa}\right)$ would correspond to

161 pore fluid pressures of 38 - 96 \% lithostatic pressure, i.e. from hydrostatic to near

162 lithostatic. Time is not explicitly scaled in the experiments but imposed loading rates

163 cover more than two orders of magnitude $(0.1-25 \mathrm{~mm} / \mathrm{min})$ similar to post- and

164 interseismic deformation rates in nature ( $\mathrm{mm} /$ day $-\mathrm{mm} /$ year) in order to test possible

165 time scale dependencies (or independencies) of creep signals.

\section{Experimental observations and analysis}

167 Analogue fault slip in our experiments is characterized by quasi-periodic stress drops

168 (Figure 2). Quasi-periodic stress drops are preceded by smaller, episodic events

169 (Figure 3). The sizes and recurrence intervals of periodic stress drops are

170 systematically related to the applied normal load and loading rate (Figure 4). This

171 observation is consistent with normal load and loading rate both determining the yield

172 strength according to rate-and-state friction theory (Scholz, 1998). A regular stick-slip

173 behavior is consistent with a characteristic earthquake model where episodic slip

174 occurs at a certain stress level determined by the yield strength and causes relaxation 
175

176

177

178

179

180

181

182

183

184

185

186

187

188

189

190

191

192

193

194

195

196

197

198

199

to a certain lower stress level determined by the residual friction and the stiffness of the loading system.

Beside periodic and episodic stress drops, representing slip during earthquakes and slow slip events, a significant amount of long-term laboratory fault slip occurs as transient creep (accelerating stable slip) between episodic failures. This stable slip during the "stick"-phase causes the stress curves in Figures 2 and 3 to deviate from a linear, elastic loading path. Instead of an ideal "saw tooth” pattern characterizing stress histories of perfect stick-slip, a "shark fin” pattern emerges for the observed stick-creep-slip. In the experiments, up to $80 \%$ of long-term fault slip might be taken up by creep at low effective normal stresses resulting in seismic coupling coefficients (the ratio of seismic to total fault slip) of $<0.2$ for very weak faults (Figure 2C). At high normal stresses, seismic coupling increases to $>0.8$ for strong faults in the experiments.

Detailed inspection of the stress loading paths (Figure 5 A) and interseismic creep signals (Figure $5 \mathrm{~B}$ ) and their time-derivates (i.e. loading and slip rates, Figure $5 \mathrm{C}$ and D) sheds light on the time and stress dependencies of laboratory fault creep. Accordingly, stress in the inter-event time (which is normalized to a unit interval here) accumulates in a more transient, non-linear fashion for weak faults than it does for strong faults (red versus blue curves in Figure 5 A and C). Strong faults show a stressing rate which is almost consistent with elastic loading except prior to an event (i.e. runs parallel long-term rate in Figure 5 C) while stressing rates of weak faults vary by more than an order of magnitude. Slip varies consistently with loading. Accordingly, slip accumulates in a more non-linear for strong faults than it does for weak faults (Figure 5 B) covering two orders of magnitude in slip rate versus less than one, respectively (Figure 5 D). 
200 Connecting stress and strain allow us to describe the creep behavior of our fault

201 analogues as follows: Creep along strong laboratory faults accelerates at rather

202 constant stressing rate late in the interseismic period leading to episodic failure

203 ("precursory slip”). Weak faults instead creep at higher rates throughout the

204 interseismic period but more continuously and at progressively decreasing stressing

205 rate. Moreover, strong faults reach only about half of the long-term fault slip rate

206 towards the very end of the loading cycle, whereas weak faults may creep at almost

207 the long-term rate for the second half of the loading cycle.

208 In order to analyze the creep behavior systematically as controlled by extrinsic factors

209 (normal stress and loading rate) we attempted to quantify the non-linearity (or

210 transience) of stress and slip accumulation by a single, dimensionless parameter.

211 Therefore we calculated the area beneath the normalized stress and strain

212 accumulation curves in Figure 5 A and B, respectively, which we call the unit stress

213 and unit strain integrals (Figure 5E). Clearly, these measures of transience decrease

214 systematically with increasing applied normal stress or fault strength as expected from

215 the observations before. However, they do not correlate with loading rate, an

216 observation that is not intuitive but useful as will be discussed below. The positive

217 correlation between the unit stress and slip integrals (Figure 5F) indicates the

218 consistency of our independent stress and stain observations and is a direct result of

219 the intrinsic velocity weakening behavior of the laboratory fault.

220 Irrespective of fault strength, episodic slip events of various speeds occur at high

221 stress level modulating the interseismic creep signal in the late stage of the analogue

222 seismic cycle (Figure 3). Preliminary analysis suggests that these precursor events

223 increase systematically in number and size as the fault evolves towards failure. 


\subsection{Inversion of fault properties and state from creep signals}

227 The observation of continuous and transient creep signals as well as episodic slow 228 slips which are systematically linked to fault properties and maturity of the loading 229 cycle or stress level but independent of loading rate bear important implications for 230 the interpretation of fault creep records as observable proxies for fault strength and 231 seismic potential. Fault creep records in nature are generally short with respect to the 232 seismic cycle. The results obtained here suggest that any creep record, though only a 233 snapshot of the full seismic cycle, might bear important information on long-term 234 fault properties and hazardous behavior.

235 Using the analog fault observations from the here presented experiments, an empirical 236 inversion scheme as proposed in Figure 6 can be applied, where inaccessible fault 237 properties like fault strength, seismic coupling, stress drop and recurrence interval can 238 be inferred from the observable transience of interseismic creep signals. Here, creep 239 transience (CT) is defined as

$$
\mathrm{CT}=2 \cdot(1-2 \cdot \text { unit slip integral })
$$

241 in order to derive a dimensionless (and therefore scale-independent) parameter which

242 varies between 0 (linear strain accumulation) and 1 (non-linear, highly transient strain 243 accumulation).

244 Linear regression analysis of the experimentally derived data plotted in such a scheme

245 indicates a significant correlation between creep signals and fault properties and 246 behavior but independence of loading rate. More specifically, fault strength, seismic 247 coupling, stress drop as well as recurrence period show a positive linear or log-linear 248 dependency with CT $\left(\mathrm{R}^{2}>0.6-0.8\right)$. 
Importantly, no significant correlations exist between any of the parameters with

250 loading rate. This is indicated by the rather horizontal or scattered distribution of data

251 from subsets with the same fault strength measured at different velocities in Figure 6

252 as well as the collapse of time-series data from such subsets in Figure 5. The fact that

253 the systematics found experimentally are loading rate independent suggest that short-

254 term observations can be extrapolated to larger earthquakes and longer recurrence

255 intervals. I.e. this timescale independency opens the opportunity to generalize fault

256 properties or behavior derived during aftershocks sequences or earthquake swarms or

257 from repeating events to longterm (multiple seismic cycles) fault behavior.

258 An observation not quantified in detail here is the occurrence of precursor slip events

259 of different scale and velocity which systematically increase in number and size

260 towards the end of a seismic cycle (Figure 3). Several large earthquakes in subduction

261 zones have actually been preceded by accelerating foreshock activity (e.g. Bouchon et

262 al., 2013). Especially the recent 20148.1 Pisagua earthquake offshore Chile showed

263 accelerating foreshock activity with a decrease in b-value (representing an increase in

264 the number of large events relative to small events) over the decade preceding the

265 main shock (Schurr et al., 2014). If such a systematic behavior can be generalized and

266 physically explained it should lead to a better ability to forecast earthquakes.

\subsection{Revisiting creep records along the San Andreas Fault}

268 In order to test and apply our proposed inversion scheme, we use the longest creep

269 records available and revisit the San Andreas Fault data. California creepmeters have

270 been installed across the San Andreas Fault in the late 1960s (Schulz et al., 1982),

271 geodetic surveys took place since the mid-1970s (Burford and Harsh, 1980; Lisowski

272 and Prescott, 1981) and surface velocities from space-geodetic measurements are

273 available since about a decade (e.g., Bürgmann et al., 2000; Titus et al., 2006). For a 
mean recurrence interval of large Californian earthquakes of about $150 \pm 50$ years

275 along any SAF segment (e.g. Zielke et al., 2010), the observation time frame

276 generally represents less than half of the seismic cycle length. Nevertheless, the

277 records are probably the best data we can get today.

278 Seismic and aseismic strike-slip along the central SAF (cSAF) accounts for most of 279 the Pacific-Great Valley microplate relative motion in central California (Thatcher, 280 1979; Lisowski and Prescot, 1981, Titus et al., 2006; Rolandone et al., 2008; Ryder 281 and Bürgmann, 2008). As suggested by over 40 years of creep and earthquake 282 records, the central section of the cSAF creeps continuously at a decadal scale at 283 about $28 \mathrm{~mm} / \mathrm{a}$ at seismogenic depth $(0-12 \mathrm{~km}$, Schulz et al., 1982, Titus et al., 284 2006, Rolandone et al., 2008). This long-term creep is modulated by shorter term transients presumably very shallow $(<5 \mathrm{~km})$ and related to earthquakes (Lisowski and Prescott, 1981; Thurber, 1996). At seismogenic depths repeating microearthquakes occur (Nadeau and McEvilly, 2004) indicating that locally and/or transiently, velocity weakening behavior is established along the fault. Noticeably, the current creep of 289 cSAF is only about $80-90 \%$ of the far-field, tectonic loading rate (31 - $35 \mathrm{~mm} / \mathrm{a}$, 290 Titus et al., 2006, Rolandone et al., 2008; Ryder and Bürgmann, 2008) suggesting a 291 slip deficit of few millimeter accumulating each year. Right-lateral shear strains in the 292 sidewalls of the cSAF are evidently very small (Rolandone et al., 2008, Savage, 2009) 293 suggesting a small stressing rate. Episodic slow slip events as they occur late in the 294 interseismic period in our experiments (Figure 3) have been reported as potential 295 earthquake pre-cursors along the SAF by Thurber (1996) and Thurber and Sessions 296 (1998) based on temporal cross-correlation of creepmeter records and seismological 297 catalogues. Though the correlations they found were statistically significant, the 298 feedback mechanism remained unclear. Noticeably, they did not find a clear spatial 
relation between the loci of creep and earthquakes which would be required by our model. Moreover, they assigned creep to the very shallow crust $(<5 \mathrm{~km})$ and not to seimogenic depths. Whilst the adjoining segments ruptured in large earthquakes in 1906 (San Francisco) and 1857 (Fort Tejon), the creeping section of the cSAF has not experienced large earthquakes in the historic past ( 300 years).

In the light of the experiments done in this study the key question is: Does the absence of large earthquakes, the high and continuous creep rates as well as the low shear strain accumulation serves as a good indicator that this fault segment poses no seismic hazard?

Applying the empirical inversion scheme established above (Figure 6), we would infer first that the creeping section of the cSAF is a very weak fault based on the rather linear slip accumulation signal (Schulz et al., 1982, Titus et al., 2006) and low stressing rate (Rolandone et al., 2008, Savage, 2009). This is consistent with previous findings based on the observation of low resolved shear stresses along the creeping section and absence of a heat flow anomaly (Brune et al., 1969, Lachenbruch and Sass, 1980, Zoback et al., 1987).

The cSAF shows therefore kinematic similarity to our weak fault analogue characterized dynamically by low seismic coupling and small stress drops during earthquakes. This may however not mean that the seismic potential is low. In contrast: Because stress drop is only a weak measure of earthquake size, which scales dominantly with the rupture area, and because low seismic coupling (or vice versa a large amount of interseismic creep) just stretches the recurrence intervals of potentially large earthquakes. We will elaborate on this effect in the next section. 
324 Because of the empirically found correlation between fault strength and creep, the net

325 effect of creep on the recurrence interval of earthquakes should not only take into

326 account the stretching of the recurrence interval due to creep but also a modification

327 of recurrence interval due to changes in strengths (Figure 4). Such a scenario is

328 illustrated in Figure 7.

329 Quantitatively, creep lengthens the (effective) recurrence interval to

$$
t^{*}=1 /(1 \text {-creep) }
$$

331 For example a fault where $50 \%$ of longterm slip is accommodated aseismically

332 requires twice as much time to reach a certain stress level again. However, because

333 creep correlates with fault weakness and weaker faults fail at lower stress level in

334 quicker succession for the same far field stressing rate (Figure 4), this lengthening

335 effect is to some degree counterbalanced by shorter recurrence intervals.

336 In Figure 7 we plot the effective recurrence time observed in our experiments in

337 relation to creep on faults of variable strength and model the data as the combined

338 result of the competing effects of “creep lengthening” (according to eq. (iii)) and

339 "weakness shortening”. The latter effect is taken into account by fitting an

340 exponential relation of the form

$$
\mathrm{t}^{* *}=\mathrm{e}^{\wedge}(-A \mathrm{x} \text { creep })
$$

342 to the data. Parameter $A$ is an empirically derived proxy for the relation between

343 strength and recurrence interval and varies between 4 and 6 in our example. The net

344 effect of “creep lengthening” and "weakness shortening” of recurrence intervals, i.e.

345 the effective recurrence interval, is then simply 


$$
\mathrm{t}=\mathrm{t}^{*} \times \mathrm{t}^{* *}=1 /\left(1 \text {-creep) } \mathrm{e}^{\wedge}(-A \mathrm{x} \text { creep })\right. \text {. }
$$

347 For the parameter space realized in our experiments recurrence time is always shorter

348 than on faults without creep, i.e. the weakness effect dominates the recurrence

349 behavior such that more creeping faults have systematically shorter recurrence times.

350 However, at least theoretically our model predicts for very weak faults (not realized in

351 our experiments) with very low seismic coupling coefficients and very high creep

352 amounts, the lengthening effect should start dominating and consequently the

353 effective recurrence intervals should become longer than without creep. For creep

354 amounts exceeding 98\% effective recurrence times may well exceed any historical

355 record for fast creeping faults (Figure 7). In the extreme such a seismically nearly

356 uncoupled, very weak fault appears as seismically silent over many human

357 generations - obviously a chimera.

\subsection{Creep on continental vs. subduction megathrusts}

359 Locking pattern of continental and subduction megathrusts show a striking qualitative

360 difference: While continental megathrusts, e.g. the Himalayan main thrust, show

361 homogeneous and high locking with little interseismic creep (Stevens and Avouac,

362 2015), subduction megathusts, like the Chilean subduction zone, show a patchy

363 locking pattern indicating a significant amount of creep (e.g. Saillard et al., 2017).

364 According to our experiments, and in line with theory, such a qualitative difference

365 can be explained by higher amounts water entrained into subduction megathrust

366 compared to continental settings, lowering the effective normal load and this

367 enhancing creep. However, other explanations exist like differences in lithology and

368 even lack of offshore geodetic coverage. 


\section{Conclusion}

371 Based on stick-slip experiments using a labscale fault analogue, we explored the slip

372 behavior of seismogenic faults and tested the potential to derive information on fault

373 properties and state from kinematic observables. We showed that the stress buildup

374 between episodic failures (analogue earthquakes) is non-linear and anti-correlated

375 with the creep signals. According to our experiments the transience of stress buildup

376 and creep is controlled primarily by fault normal stress, i.e. related to frictional

377 strength and/or pore-fluid pressure, and systematically reflect the seismic coupling

378 coefficient and maturity of the seismic cycle. Application of these systematics to the

379 creeping section of the central San Andreas fault suggests that this fault branch may

380 not be aseismic on the long term (millennia scale) but is in a late stage of a seismic

381 cycle which exceeds historic records. The qualitative difference in creep on

382 megathrusts between homogenously fully locked continental versus heterogeneously

383 locked subduction megathrusts may be similarly explained by the presence of water in

384 oceanic settings.

\section{Acknowledgements}

386 This study has been partially funded by the German Research Foundation (DFG)

387 collaborative research center SFB1114 “Scaling Cascades in Complex Systems”, 388 project B01. 
411 (normalized), (C) interseismic stress rate (normalized), (D) interseismic slip rate 412 (normalized), (E) Variation of unit stress and slip integrals over the parameter space

\section{Figure Captions}

Figure 1: Analogue earthquake experimental setup: (A) side (camera) view of the sample (rice) in a transparent shear cell in situ in the ring-shear tester, boundary conditions and observables indicated; PIV velocities are representative of a slip event. (B) sketch of the ring-shear tester setup (modified from Schulze (2003)) with PIV camera position indicated.

Figure 2: Stress and strain time-series of laboratory faults: (A) Stress time series measured during velocity stepping tests under variable normal loads simulating seismic and aseismic slip along very weak to strong fault slip. Note the periodic stress drops representing analogue earthquakes. (B) Slip time series for very weak and strong faults derived by PIV. (C) Variation of seismic coupling over the parameter space tested here. Note the sensitivity of seismic coupling to normal load and insensitivity to loading rate.

Figure 3: Examples of precursory slip events along laboratory faults (from Rosenau et al., 2017): (A) stress time series, (B) Histogram of number of slow slip events per unit interseismic time interval. Note the increase of precursory events in size and number towards the end of the seismic cycle.

Figure 4: Dependency of recurrence interval and stress drop on loading rate and normal load over the parameters space tested here.

Figure 5: Systematics of interseismic stress-strain relationships for laboratory faults: (A) interseismic stress accumulation (normalized), (B) interseismic slip accumulation 
413 tested here, (F) correlation of unit stress and slip integrals indicating velocity

414 weakening behaviour.

415 Figure 6: Dependency of creep signal transience on laboratory fault properties: (A)

416 fault strength as a function of creep transience, (B) seismic coupling as a function of

417 creep transience, (C) stress drop as a function of creep transience, (D) recurrence

418 period as a function of creep transience.

419 Figure 7: Modelling the effect of fault creep and strength on recurrence time of

420 earthquakes. Experimental data are fitted by theoretical model taking into account two

421 competing effect: Fault creep lengthens recurrence intervals (“creep lengthening

422 effect”) while weakening faults should shorten recurrence intervals ("weakness

423 shortening effect”). The effective recurrence is dominated by the weakness effect for

424 faults creeping up to 98\%. However, faults which accumulate $>98 \%$ of fault slip

425 aseismically may still generate earthquakes with recurrence periods exceeding

426 historical records (California earthquake history shown as example). 


\section{References:}

1. Adam, J., O. Oncken, N. Kukowski, J. Lohrmann, S. Hoth, J. L. Urai, W. van der Zee, J. Schmatz, B. Wieneke, and K. Pfeiffer (2005), Shear localisation and strain distribution during tectonic faulting - New insights from granularflow experiments and high-resolution optical image correlation techniques, Journal of Structural Geology, 27(2), 183-301.

2. Bedford, J., et al. (2013), A high-resolution, time-variable afterslip model for the 2010 Maule Mw=8.8, Chile megathrust earthquake, Earth and Planetary Science Letters, 383, 26-36.

3. Bokelmann, G. H. R. (2003), Long-term creep-rate changes and their causes, Geophysical Research Letters, 30(8).

4. Bouchon, M., V. Durand, D. Marsan, H. Karabulut, and J. Schmittbuhl (2013), The long precursory phase of most large interplate earthquakes, Nature Geoscience, 6(4), 299-302.

5. Brune, J. N., T. L. Henyey, and R. F. Roy (1969), Heat flow, stress, and rate of slip along the San Andreas Fault, California,Journal of Geophysical Research, 74(15), 3821--3827.

6. Burford, R. O., and P. W. Harsh (1980), Slip on the San Andreas fault in central California from alinement array surveys, Bulletin of the Seismological Society of America, 70(4), 1233-1261.

7. Byerlee, J. (1978), Friction of rocks, Pageoph, 116, 615-626.

8. Bürgmann, R., D. Schmidt, R. M. Nadeau, M. d'Alessio, E. Fielding, D. Manaker, T. V. McEvilly, and M. H. Murray (2000), Earthquake Potential 

1182.

9. Hardebeck, J. L., and A. Aron (2009), Earthquake Stress Drops and Inferred Fault Strength on the Hayward Fault, East San Francisco Bay, California, Bulletin of the Seismological Society of America, 99(3), 18011814.

10. Ide, S., G. C. Beroza, D. R. Shelly, and T. Uchide (2007), A scaling law for slow earthquakes, Nature, 447(7140), 76-79. (2012), Propagation of Slow Slip Leading Up to the 2011 M-w 9.0 TohokuOki Earthquake, Science, 335(6069), 705-708.

12. Lachenbruch, A. H., and J. H. Sass (1980), Heat flow and energetics of the 463 San Andreas Fault Zone, Journal of Geophysical Research: Solid Earth, 85(B11), 6185--6222. (2013), A Record of Large Earthquakes during the Past Two Millennia on the Southern Green Valley Fault, California, Bulletin of the Seismological Society

14. Lisowski, M., and W. H. Prescott (1981), Short-range distance measurements along the San Andreas fault system in central California, 1975 to 1979, Bulletin of the Seismological Society of America, 71(5), 1607-1624. coupling and coseismic rupture extent of the $2011 \mathrm{MW}=9.0$ Tohoku-oki earthquake, Geophysical Research Letters, 38(17). 
16. Moreno, M., M. Rosenau, and O. Oncken (2010), 2010 Maule earthquake slip correlates with pre-seismic locking of Andean subduction zone, Nature, 467(7312), 198-202.

17. Moreno, M., C. Haberland, O. Oncken, A. Rietbrock, S. Angiboust, and O. Heidbach (2014), Locking of the Chile subduction zone controlled by fluid pressure before the 2010 earthquake, Nature Geoscience, 7(4), 292-296.

18. Nadeau, R. M., and T. V. McEvilly (2004), Periodic Pulsing of Characteristic Microearthquakes on the San Andreas Fault, Science,303(5655), 220-222.

19. Noda, H., and N. Lapusta (2013), Stable creeping fault segments can become destructive as a result of dynamic weakening,Nature, 493(7433), 518-+.

20. Peng, Z. G., and J. Gomberg (2010), An integrated perspective of the continuum between earthquakes and slow-slip phenomena, Nature Geoscience, 3(9), 599-607.

21. Rogers, G., and H. Dragert (2003), Episodic tremor and slip on the Cascadia subduction zone: The chatter of silent slip, Science,300, 1942-1943.

22. Rolandone, F., R. Bürgmann, D. C. Agnew, I. A. Johanson, D. C. Templeton, M. A. d'Alessio, S. J. Titus, C. DeMets, and B. Tikoff (2008), Aseismic slip and fault-normal strain along the central creeping section of the San Andreas fault, Geophysical Research Letters, 35(14), n/a--n/a.

23. Rosenau, M., J. Lohrmann, and O. Oncken (2009), Shocks in a box: An analogue model of subduction earthquake cycles with application to seismotectonic forearc evolution, Journal of Geophysical Research, 114(B1). 
24. Rosenau, M., F. Corbi, S. Dominguez (2017): Analogue earthquakes and seismic cycles: Experimental modelling across timescales, Solid Earth, doi: 10.5194/se-2016-165

25. Rudolf, M., Rosenau, M. , Ziegenhagen T., et al. (2019): Smart speed imaging in Digital Image Correlation: Application to seismotectonic scale modelling, Front. Earth Sci., https://doi.org/10.3389/feart.2018.00248

26. Ruiz, S., M. Metois, A. Fuenzalida, J. Ruiz, F. Leyton, R. Grandin, C. Vigny, R. Madariaga, and J. Campos (2014), Intense foreshocks and a slow slip event preceded the 2014 Iquique Mw 8.1 earthquake, Science.

27. Ryder, I., and R. Bürgmann (2008), Spatial variations in slip deficit on the central San Andreas Fault from InSAR, Geophysical Journal International, 175(3), 837--852.

28. Saillard, M., L. Audin, B. Rousset, J. P. Avouac, M. Chlieh, S. R. Hall, L. Husson, and D. L. Farber (2017), From the seismic cycle to long-term deformation: linking seismic coupling and Quaternary coastal geomorphology along the Andean megathrust, Tectonics, 36(2), 241-256.

29. Savage, J. C. (2009), Comment on “Aseismic slip and fault-normal strain along creeping section of the San Andreas Fault” by F. Rolandone et al., Geophysical Research Letters, 36(13), n/a--n/a.

30. Scholz, C. H. (1989), Mechanics of Faulting, Ann. Rev. Earth Planet. Sci., 17, 309-334.

31. Scholz, C. H. (1998), Earthquakes and friction laws, Nature, 391, 37-42. 
32. Schulze, D. (2003), Time- and velocity-dependent properties of powders effecting slip-stick oscillations, Chemical Engineering \& Technology, 26(10), 1047-1051.

33. Schurr, B., et al. (2014), Gradual unlocking of plate boundary controlled initiation of the 2014 Iquique earthquake, Nature,512(7514), 299-+.

34. Shirzaei, M., and R. Buergmann (2013), Time-dependent model of creep on the Hayward fault from joint inversion of 18years of InSAR and surface creep data, Journal of Geophysical Research-Solid Earth, 118(4), 1733-1746.

35. Stevens, V.L., Avouac, J.-P. (2015), Interseismic coupling on the main Himalayan thrust. Geophysical Research Letters,doi:10.1002/2015GL064845

36. Thatcher, W. (1979), Horizontal crustal deformation from historic geodetic measurements in southern California, Journal of Geophysical Research: Solid Earth, 84(B5), 2351--2370.

37. Thurber, C. H. (1996), Creep events preceding small to moderate earthquakes on the San Andreas fault, Nature, 380, 425 - 428.

38. Titus, S. J., C. DeMets, and B. Tikoff (2006), Thirty-Five-Year Creep Rates for the Creeping Segment of the San Andreas Fault and the Effects of the 2004 Parkfield Earthquake: Constraints from Alignment Arrays, Continuous Global Positioning System, and Creepmeters, Bulletin of the Seismological Society of America, 96(4B), S250-S268.

39. Wei, M., Y. Kaneko, Y. J. Liu, and J. J. McGuire (2013), Episodic fault creep events in California controlled by shallow frictional heterogeneity, Nature Geoscience, 6(7), 566-570. 
542

543

544

545

546

40. Zielke, O., J. R. Arrowsmith, L. G. Ludwig, and S. O. Akçiz (2010), Slip in the 1857 and Earlier Large Earthquakes Along the Carrizo Plain, San Andreas Fault, Science, 327(5969), 1119-1122.

41. Zoback, M. D., et al. (1987), New Evidence on the State of Stress of the San Andreas Fault System, Science, 238(4830), 1105-1111. 
Figure 1
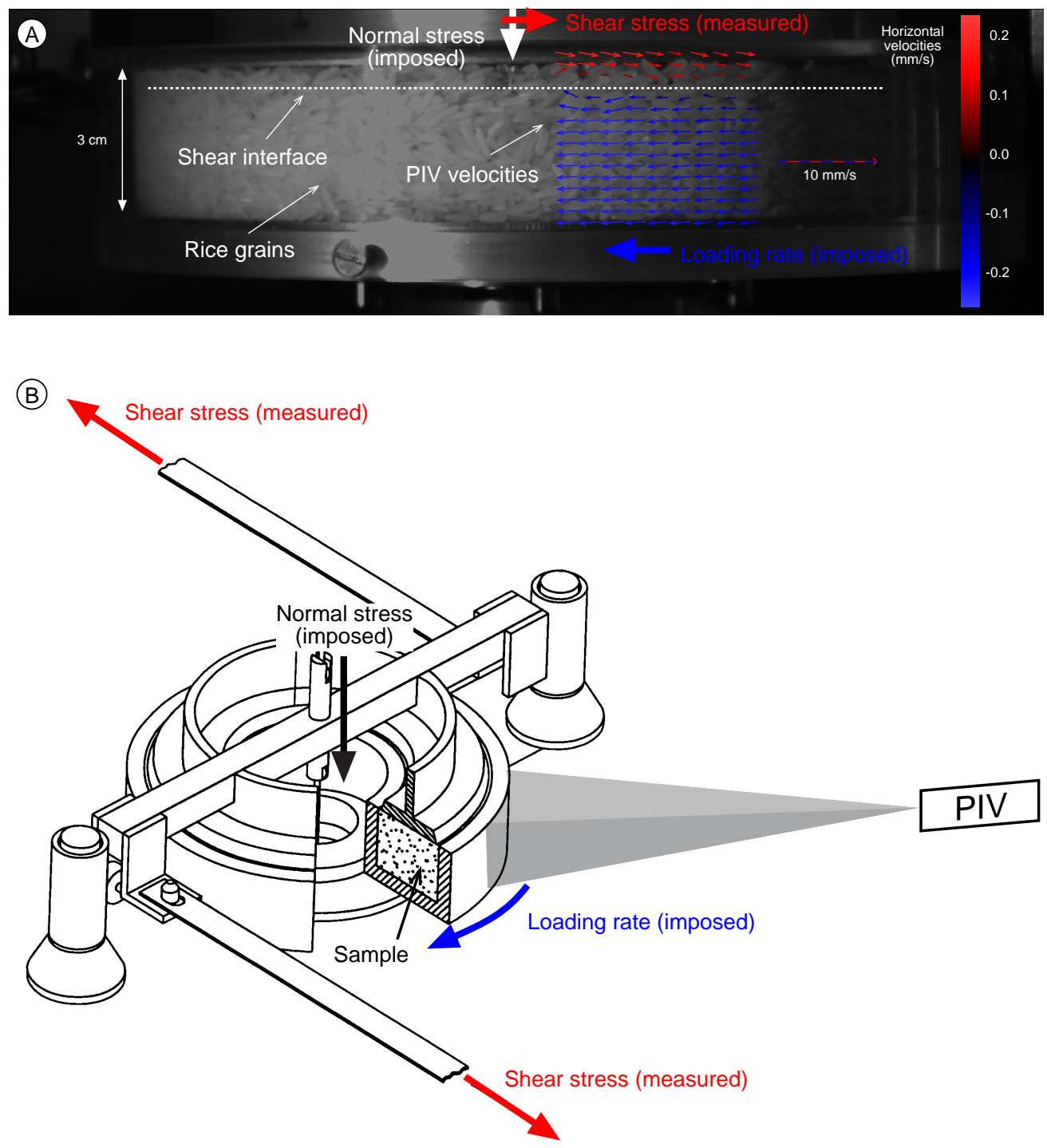
Figure 2

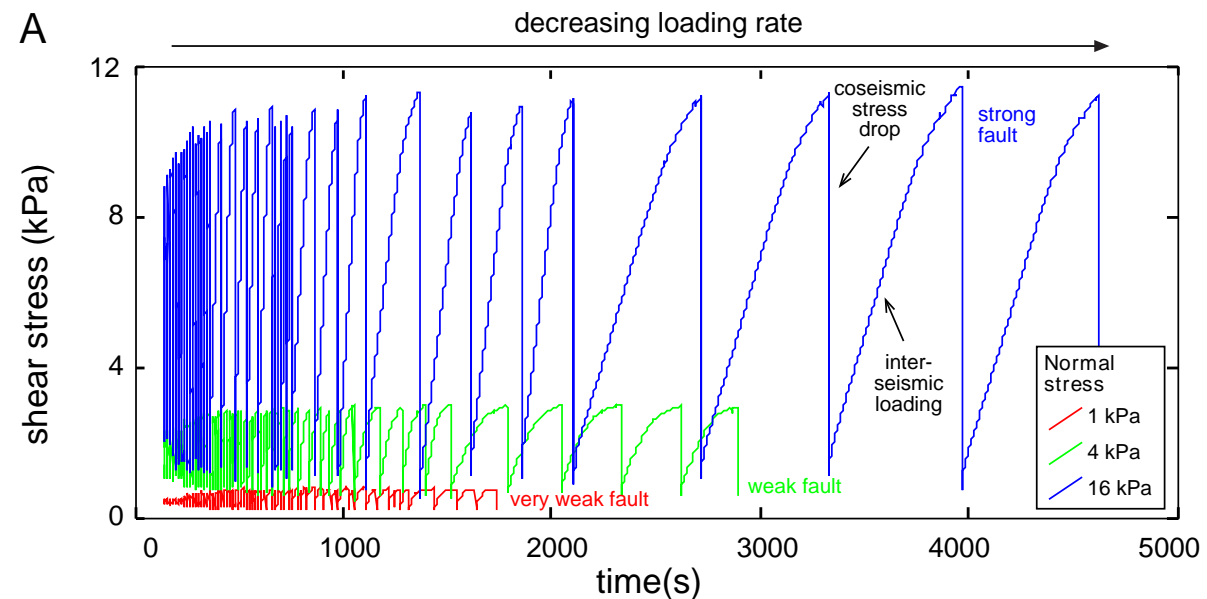
B very weak fault strong fault

C seismic coupling $16 \mathrm{kPa}$

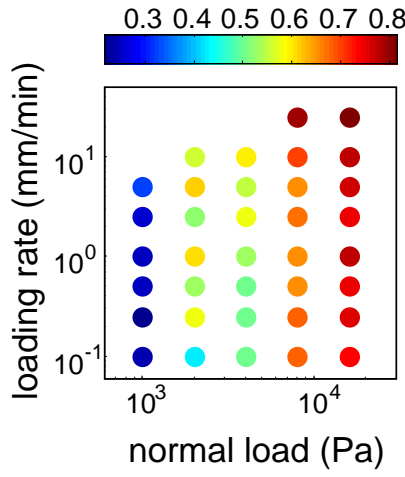

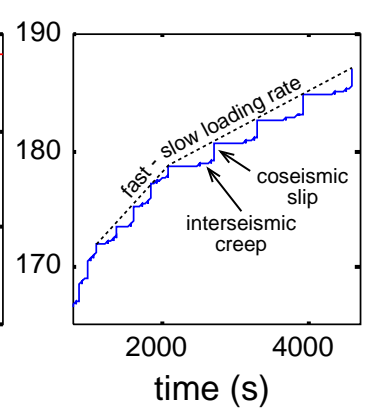

time (s)

normal load (Pa) 
Figure 3
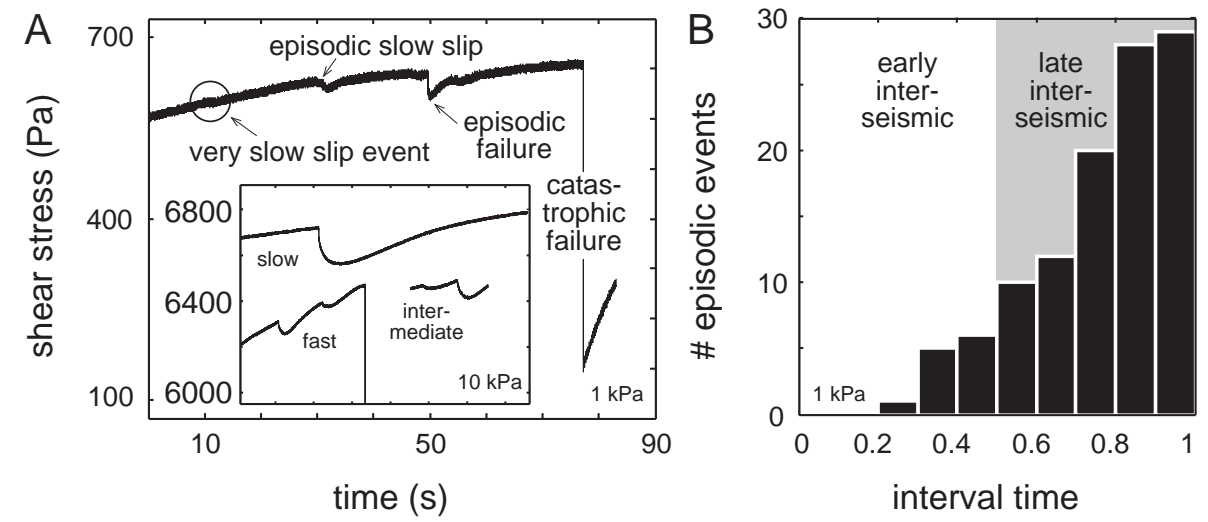
Figure 4

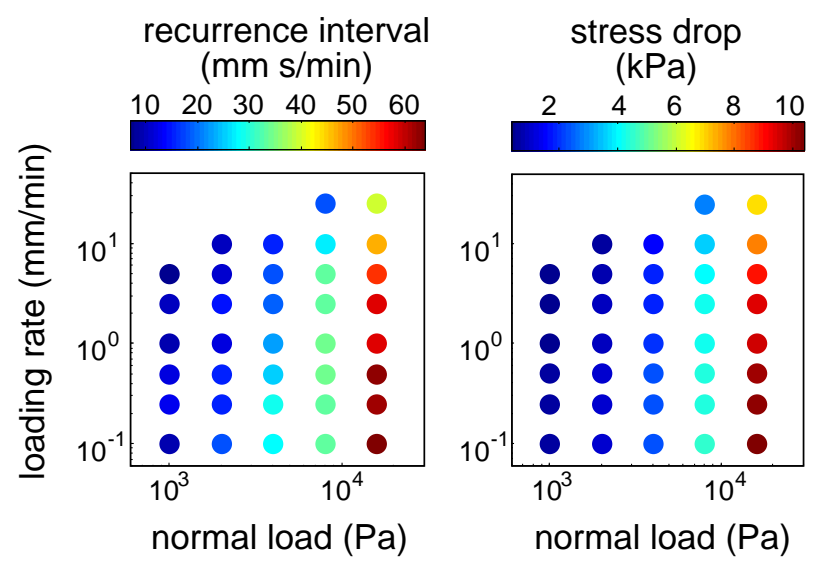


Figure 5
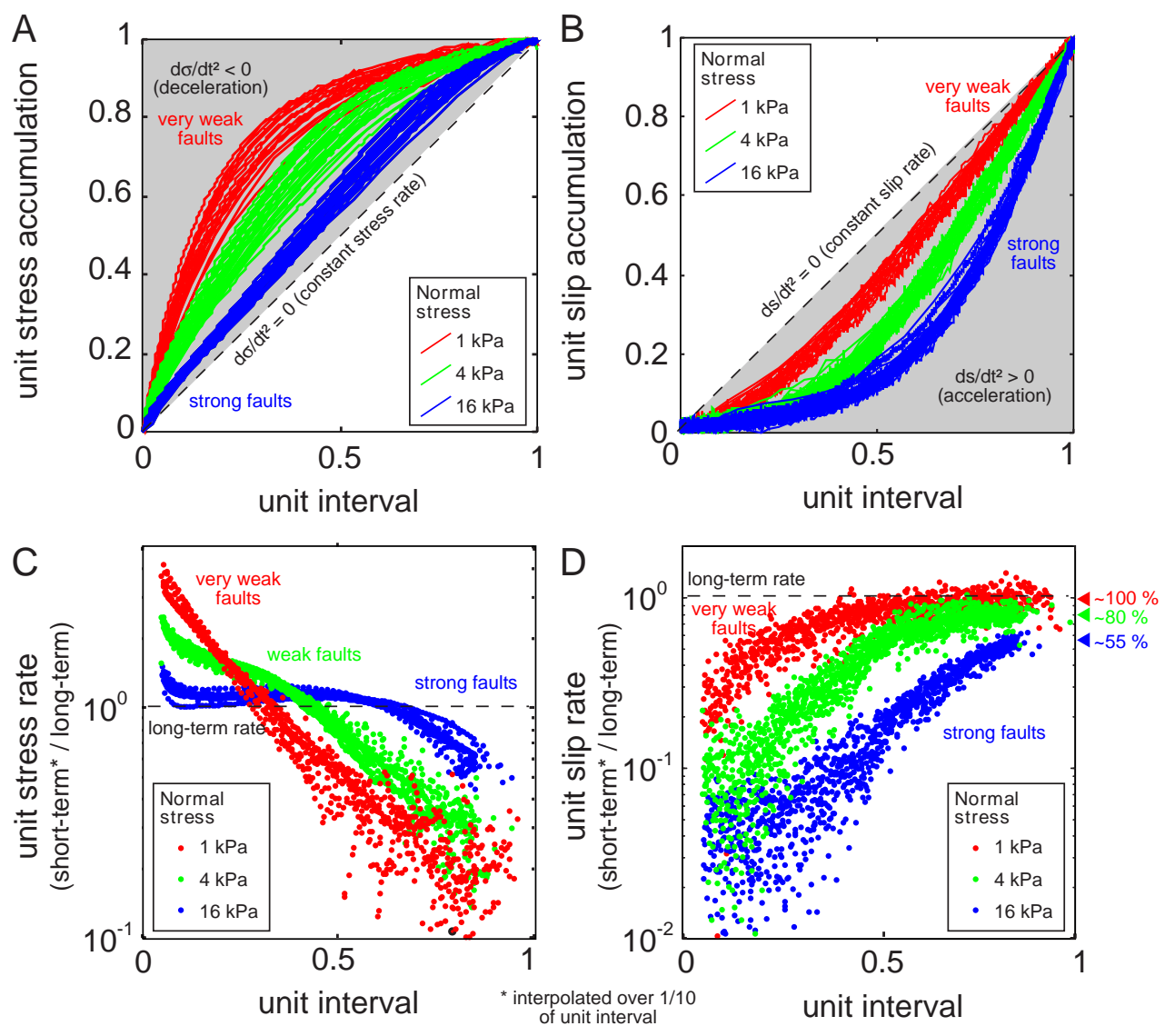

E

$$
\text { unit stress integral }
$$

$$
\text { unit slip integral }
$$

F normal stress (kPa)
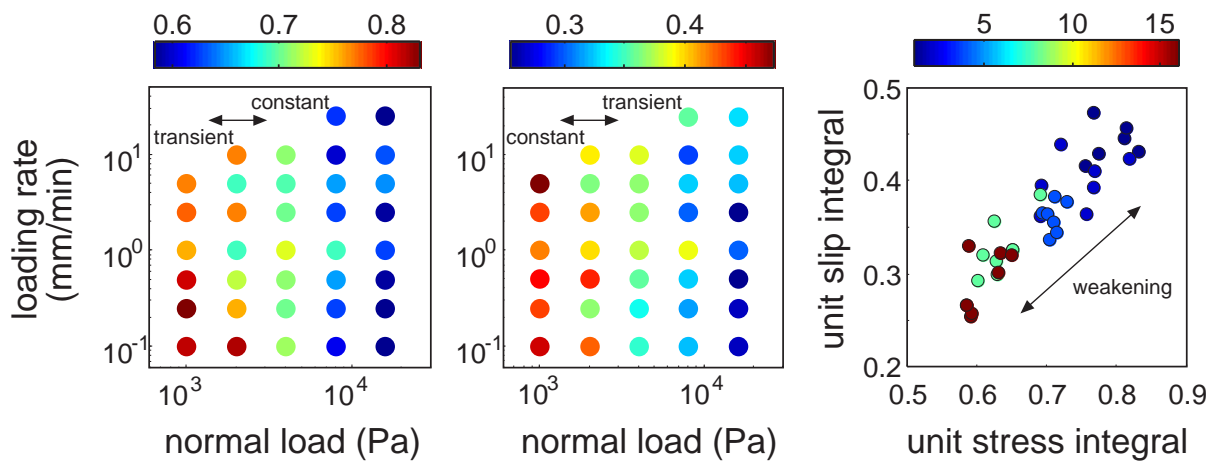
Figure 6
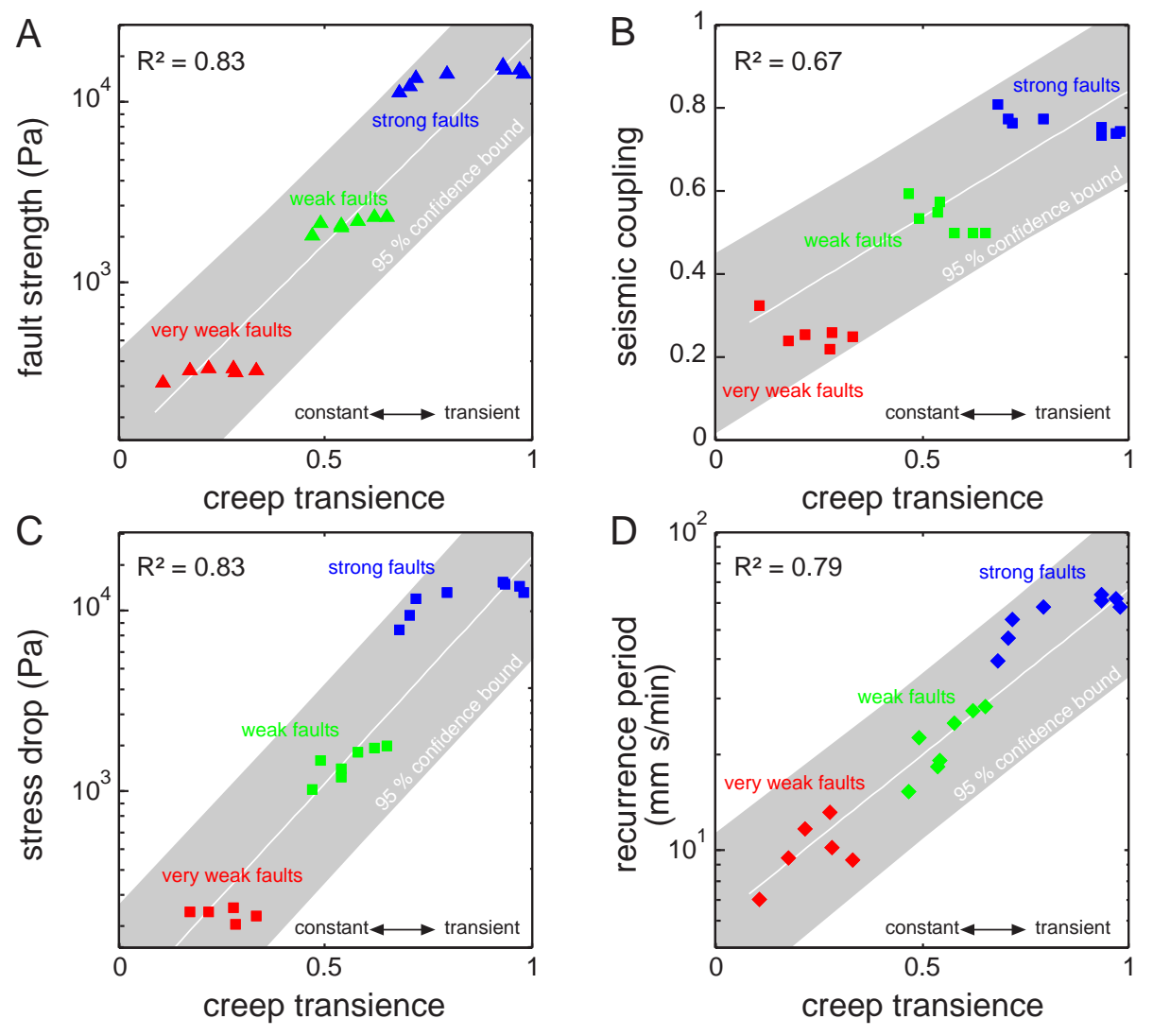
Figure 7
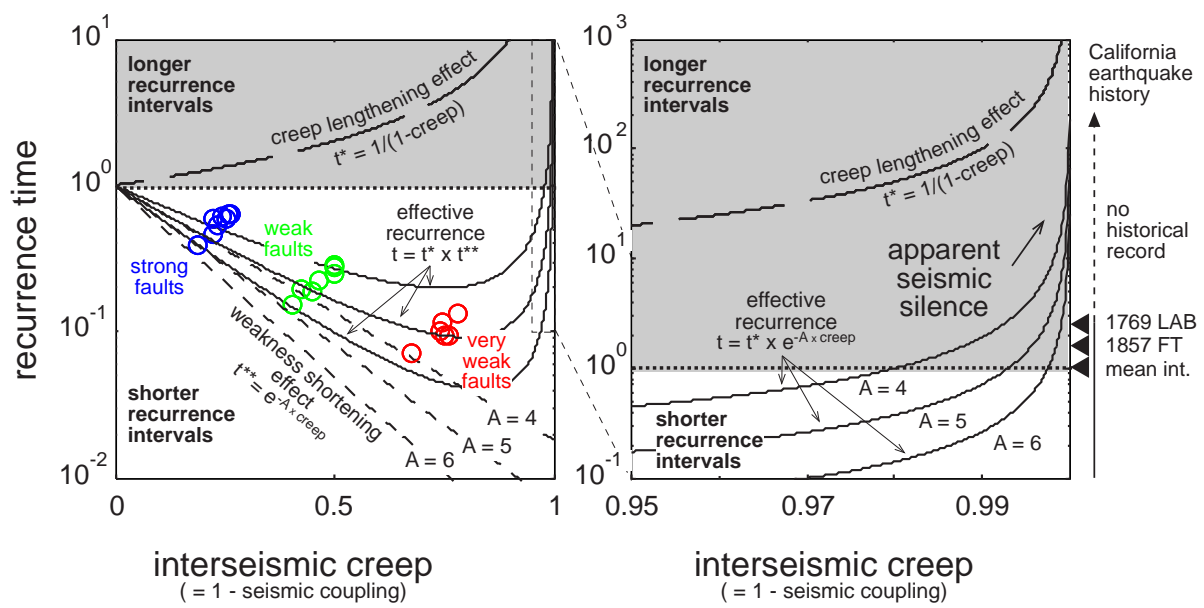